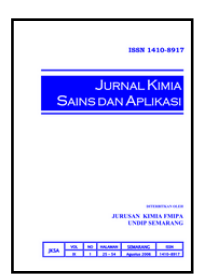

\title{
Isolasi dan Identifikasi Senyawa Golongan Alkaloid dari Rimpang Lengkuas Merah (Alpinia purpurata)
}

\author{
Muhammad Untoro $^{a}$, Enny Fachriyah ${ }^{a^{*}}$, Dewi Kusrini ${ }^{a}$ \\ a Organic Chemistry Laboratory, Chemistry Department, Faculty of Sciences and Mathematics, Diponegoro University, Jalan Prof. \\ Soedarto, Tembalang, Semarang \\ * Corresponding author: enny.fachriyah@live.undip.ac.id
}

\begin{tabular}{|c|c|}
\hline Article Info & Abstract \\
\hline & Isolation and Identification of Alkaloid Group Compounds from Red Galangal Rhizome \\
\hline $\begin{array}{l}\text { Keywords: } \\
\text { Red galangal } \\
\text { rhizome (Alpinia } \\
\text { purpurata), alkaloid, } \\
\text { piperine. }\end{array}$ & $\begin{array}{l}\text { (Alpinia purpurata) have been performed. This study aims to isolate and identify the } \\
\text { alkaloid group compounds of red galangal limp extract (Alpinia purpurata). From } \\
\text { phytochemical screening of dry simplicial, it was known that there were alkaloid group } \\
\text { compounds, flavonoids, saponins, and steroids. The characterization results using the } \\
\text { UV-Vis Spectrophotometer resulted in maximum wavelength at } 338 \mathrm{~nm} \text {. FTIR analysis } \\
\text { shows the presence of } \mathrm{C}-\mathrm{N}, \mathrm{C}=\mathrm{O} \text { amide, } \mathrm{C}=\mathrm{C} \text { aromatic, } \mathrm{C}-\mathrm{O} \text { ether, and } \mathrm{C}-\mathrm{H} \text { aliphatic } \\
\text { groups. Analysis using LC-MS obtained molecular weight of } 286.28 \mathrm{~g} / \mathrm{mol}[\mathrm{M}+\mathrm{H}]^{+} \text {. } \\
\text { Based on the data from these results it is suspected in pure isolates containing piperin } \\
\text { compounds }\left(\mathrm{C}_{17} \mathrm{H}_{19} \mathrm{NO}_{3}\right) \text {. }\end{array}$ \\
\hline
\end{tabular}

\begin{abstract}
Abstrak
Telah dilakukan penelitian tentang Isolasi dan Identifikasi Senyawa Golongan Alkaloid dari Rimpang Lengkuas Merah (Alpinia purpurata). Penelitian ini bertujuan untuk mengisolasi dan mengidentifikasi senyawa golongan alkaloid dari ekstrak rimpang lengkuas merah (Alpinia purpurata). Penapisan fitokimia simplisia kering diketahui bahwa terdapat senyawa golongan alkaloid, flavonoid, saponin, dan steroid. Hasil karakterisasi dengan menggunakan Spektrofotometer UV-Vis menghasilkan panjang gelombang maksimal pada $338 \mathrm{~nm}$. Analisis menggunakan FTIR terdapat gugus $\mathrm{C}-\mathrm{N}$, $\mathrm{C}=\mathrm{O}$ amida, $\mathrm{C}=\mathrm{C}$ aromatik, $\mathrm{C}-\mathrm{O}$ eter, dan $\mathrm{C}-\mathrm{H}$ alifatik. Analisis menggunakan LC-MS diperoleh berat molekul sebesar $286,28 \mathrm{~g} / \mathrm{mol}[\mathrm{M}+\mathrm{H}]^{+}$. Berdasarkan data-data dari hasil tersebut diduga dalam isolat murni mengandung senyawa piperin $\left(\mathrm{C}_{17} \mathrm{H}_{19} \mathrm{NO}_{3}\right)$.
\end{abstract}

Kata Kunci: Rimpang lengkuas merah (Alpinia purpurata), alkaloid, piperin

\section{Pendahuluan}

Indonesia merupakan negara yang terletak di salah satu kawasan tropis yang kaya akan keaneka ragaman jenis tumbuhan. Berbagai tumbuhan ini bisa dimanfaatkan sebagai sumber ramuan obat tradisional. Selain itu juga bisa sebagai sumber bahan kimia alami yang potensial untuk dikembangkan menjadi zat warna, kosmetik, bahan baku industri dan bahan aktif pestisida. Hal ini dilakukan jauh sebelum pelayanan kesehatan formal dengan obat-obatan modern menyentuh masyarakat. Salah satu jenis tumbuhan yang telah lama digunakan oleh masyarakat Indonesia sebagai tumbuhan berkhasiat adalah lengkuas merah (Alpinia purpurata) [1].

Rimpang lengkuas merah banyak digunakan sebagai obat dengan umbi berserat kasar, bagian luar mengkilat dan berwarna merah, bagian dalam berwarna putih serta mempunyai aroma yang khas [2]. Rimpang Alpinia purpurata secara luas digunakan pada pengobatan penyakit perut, kudis, panu, dan menghilangkan bau mulut. Rimpang lengkuas merah juga dianggap memiliki khasiat sebagai anti tumor dan anti kanker terutama tumor di bagian mulut dan lambung. Selain itu lengkuas merah ternyata juga mempunyai peran dalam 
memperpanjang umur simpan atau mengawetkan makanan karena aktifitas antimikroba .

Kandungan senyawa kimia dari tumbuhan yang memiliki bioaktifitas umumnya berasal dari metabolit sekunder seperti alkaloid, flavonoid, terpenoid, steroid dan lain-lain. Sedangkan hasil uji fitokimia dalam fraksi etil asetat rimpang lengkuas merah (Alpinia purpurata) dilaporkan mengandung senyawa alkaloid, terpenoid, saponin, flavonoid, fenolik dan steroid.

Penelitian Susilaningsih [3] telah berhasil mengisolasi dan mengidentifikasi 3 senyawa alkaloid pada ekstrak etil asetat yaitu 3,6-dipentil-8metilisokuinolin, 1,3-dipentil-6-metilisokuinolin, dan piperin. Sedangkan penelitian Mohd Sirat dan Liamen [4] telah berhasil mengisolasi senyawa golongan alkaloid pada rimpang lengkuas merah (Alpinia purpurata) yaitu alkaloid piperin. Senyawa alkaloid memiliki banyak efek farmakologi yaitu sebagai antiinflamasi, antimikroba, hepatoprotektor, antikanker dan meningkatkan efek antioksidan sel. Piperin terbukti menurunkan lipid peroksidase hati dan melindungi dari kerusakan oksidatif akibat induksi dari senyawa karsinogenik kimia [5]. Dalam penelitian ini dharapkan diperoleh senyawa golongan alkaloid pada rimpang lengkuas merah (Alpinia purpurata) yang dapat dikembangkan lebih lanjut.

\section{Metode Penelitian}

\section{Alat dan Bahan}

Peralatan yang digunakan dalam penelitian ini adalah gelas standar penelitian, vial, soxhlet, pipet kapiler, satu set Kromatografi Lapis Tipis (KLT), corong pisah, kolom kromatografi, oven, lemari pengering, blander, penangas air, hot plate, rotary evaporator, neraca analitik, pH meter, Spektrofotometer UV-Vis, FTIR dan LC-MS. Sampel yang digunakan dalam penelitian ini adalah rimpang lengkuas merah, n-heksana, etanol 96\%, amonium hidroksida, etil asetat, kloroform, ammonia $25 \%, \mathrm{HCl}$ (1:10), $\mathrm{HCl}$ pekat, $\mathrm{HCl} 2 \mathrm{~N}$, metanol p.a, diklorometana p.a, n-butanol p.a, aseton p.a, amilalkohol, anhidrida asam asetat, $\mathrm{H}_{2} \mathrm{SO}_{4}$ pekat, silika gel $60 \mathrm{GF}_{254}$ pereaksi Meyer $\left(\mathrm{HgCl}_{2}\right.$ dan $\left.\mathrm{KI}\right)$, pereaksi Dragendorff $\left(\mathrm{Bi}\left(\mathrm{No}_{2}\right)_{3}\right.$ dan $\left.\mathrm{KI}\right)$, serbuk $\mathrm{Mg}, \mathrm{H}_{2} \mathrm{SO}_{4}$ pekat, dan akuades.

\section{Pembuatan Simplisia Serbuk}

Sampel penelitian berupa rimpang Lengkuas Merah (Alpinia purpurata) yang diperoleh dari Balai Penelitian Tanaman Obat (BPTO) Tawangmangu, Jawa Tengah. Rimpang Lengkuas Merah dibersihkan dan dicuci terlebih dahulu. Setelah pencucian, kemudian dikeringkan dengan cara diangin-anginkan. Sampel yang sudah kering dihaluskan menjadi serbuk.

\section{Penapisan Fitokimia}

Penapisan fitokimia untuk menguji golongan kimia yang ada di dalam sampel. Sampel yang digunakan, yaitu simplisia rimpang lengkuas merah (Alpinia purpurata). Uji penapisan fitokimia yang dilakukan, yaitu uji alkaloid, flavonoid, saponin, dan steroid/triterpenoid

Isolasi alkaloid

Sebanyak 0,616 kg serbuk rimpang lengkuas merah dimaserasi dengan pelarut n-heksana hingga jernih, kemudian ampas yang telah kering dimaserasi kembali menggunakan pelarut etanol. Ekstrak etanol yang diperoleh kemudian dipekatkan dengan rotary evaporator hingga diperoleh ekstrak etanol. Ekstrak etanol ditambahkan $\mathrm{HCl} 2 \mathrm{M}$ hingga $\mathrm{pH} 3$, larutan asam ini selanjutnya diekstraksi dengan etil asetat hingga diperoleh dua lapisan, lapisan etil asetat dan lapisan air. Pada lapisan air ditambahkan $\mathrm{NH}_{4} \mathrm{OH}$ hingga $\mathrm{pH}$ 8-9, dilanjutkan ekstraksi dengan etil asetat kembali. Lapisan etil asetat yang diperoleh diuapkan kembali dan diperoleh alkaloid total.

\section{Analisis isolat}

Isolat alkaloid total diidentifikasi menggunakan pereaksi Dragendorff dan Mayer untuk memastikan bahwa senyawa yang diisolasi merupakan senyawa alkaloid. Setelah itu dianalisis menggunakan KLT untuk mengetahui komponen penyusunnya. Kemudian komponen tersebut dipisahkan dengan menggunakan kromatografi kolom dan KLT preparatif dan diuji kemurniannya dengan berbagai jenis eluen. Identifikasi struktur alkaloid yang dihasilkan dianalisis dengan Spektrofotometer UV-Vis, FTIR dan LC-MS

\section{Hasil dan Pembahasan}

\section{Penapisan Fitokimia}

Rimpang lengkuas merah yang telah menjadi simplisia kering kemudian dilakukan uji fitokimia. Berdasarkan uji fitokimia diketahui bahwa rimpang lengkuas merah (Alpinia purpurata) mengandung senyawa golongan alkaloid, flavonoid, steroid, dan saponin.

\section{Ekstraksi}

Sebanyak 0,616 kg serbuk rimpang lengkuas merah diekstraksi menggunakan pelarut $\mathrm{n}$-heksana dengan alat Soxlet yang bertujuan untuk mengikat senyawasenyawa metabolit sekunder pada rimpang lengkuas merah yang bersifat non polar seperti: steroid dan triterpenoid.

Ampas hasil ekstraksi dengan pelarut $\mathrm{n}$-heksan selanjutnya diekstraksi dengan pelarut etanol $96 \%$ menggunakan metode maserasi hingga filtratnya tidak berwarna yang menunjukkan sudah tidak ada senyawa yang terekstrak lagi. Filtrat hasil maserasi kemudian dipekatkan menggunakan alat rotary evaporator sehingga diperoleh ekstrak kental etanol. Ekstrak kental etanol ini kemudian digunakan untuk isolasi selanjutnya.

\section{Isolasi Alkaloid Total dari Ekstrak Etanol}

Ekstrak etanol yang telah didapatkan, ditambahkan larutan $\mathrm{HCl} 2 \mathrm{M}$ hingga $\mathrm{pH}$ larutan menjadi 3-4 agar terbentuk garam alkaloid. 
Setelah terbentuknya garam alkaloid tersebut selanjutnya dilakukan ekstraksi cair-cair menggunakan pelarut etil asetat. Garam alkaloid yang telah terbentuk akan larut dalam air sedangkan senyawa lain akan larut dalam fase etil asetat akibat perbedaan kelarutan. Hasil ekstraksi akan terbentuk 2 lapisan, yaitu lapisan bawah merupakan lapisan asam sedangkan lapisan atas adalah lapisan etil asetat.

Kedua lapisan tersebut kemudian dipisahkan, kemudian lapisan asam yang mengandung garam alkaloid ditambahkan $\mathrm{NH}_{4} \mathrm{OH}$ hingga $\mathrm{pH}$ larutan mencapai 8-9. Perlakuan tersebut bertujuan agar garam alkaloid membentuk alkaloid kembali. Hasil ekstraksi akan membentuk 2 lapisan yaitu lapisan etil asetat dan lapisan asam.. Selanjutnya kedua lapisan dipisahkan dan lapisan etil asetat dipekatkan dengan rotary evaporator hingga diperoleh ekstrak kental alkaloid total sebanyak 2,61 gr.

\section{Pemisahan dengan Kromatografi}

Terhadap ekstrak alkaloid total selanjutnya dilakukan pemisahan komponen menggunakan tehnik kromatografi. Analisis kandungan kimia awal dilakukan dengan Kromatografi Lapis Tipis (KLT). Fase diam yang digunakan adalah silika gel $60 \mathrm{GF}_{254}$ dan fase gerak yang digunakan adalah campuran eluen kloroform dan etil asetat perbandingan 3:1. Hasil KLT alkaloid total yang ditunjukkan pada Gambar 1.

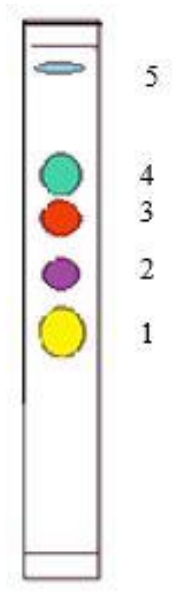

Gambar 1. Ilustrasi hasil KLT alkaloid total eluen kloroform : etil asetat (3:1)

Tabel 1: Rf dan warna noda KLT ekstrak alkaloid total

\begin{tabular}{ccc}
\hline Noda & Nilai Rf & Warna noda \\
\hline 1 & 0,46 & Kuning \\
2 & 0,56 & Ungu \\
3 & 0,73 & Orange \\
4 & 0,79 & Hijau kebiruan \\
5 & 0,96 & Biru \\
\hline
\end{tabular}

Selanjutnya ekstrak alkaloid total dilakukan pemisahan dengan metode kromatografi kolom menggunakan eluen kloroform : etil asetat (3:1). Dari tahap ini telah diperoleh 7 fraksi yang dapat dilihat pada Tabel 2.
Tabel 2: Fraksi-fraksi hasil kromatografi kolom

\begin{tabular}{cc}
\hline Fraksi & No.Vial \\
\hline I & 1 dan 2 \\
II & $3-8$ \\
III & $9-42$ \\
IV & $43-65$ \\
V & $66-93$ \\
VI & $94-144$ \\
VII & $145-170$ \\
\hline
\end{tabular}

Dari hasil pengelompokan, fraksi III merupakan fraksi terbanyak. Kemudian terhadap fraksi III dipisahkan kembali dengan metode KLT preparatif menggunakan eluen campuran kloroform:etil asetat (9:1) dan hasil elusi KLT preparatif ditunjukkan pada Gambar 2.

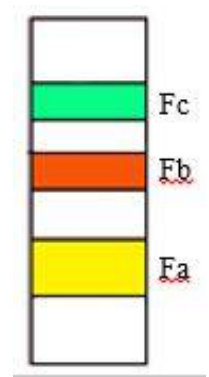

Gambar 2. Ilustrasi hasil KLT preparatif isolat alkaloid dengan eluen kloroform:etil asetat (9:1)

Diperoleh 3 pita yaitu Fa (kuning), Fb (kuning kemerahan), dan Fc (hijau kebiruan). Terhadap pita Fc (hijau kebiruan) selanjutnya dilakukan KLT Preparatif dengan eluen kloroform:etil asetat (9:1). Hasil KLT Preparatif memberikan 3 pita Fc1 (hijau pudar), Fc2 (hijau kebiruan), dan Fc3 (biru) yang ditunjukkan pada Gambar 3.

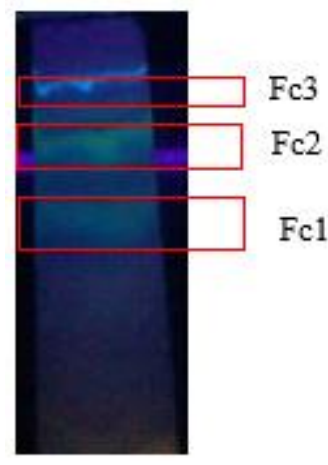

Gambar 3. Hasil KLT preparatif Fc dengan eluen kloroform:etil asetat (9:1)

Selanjutnya isolat $\mathrm{Fa}, \mathrm{Fb}, \mathrm{Fc1}, \mathrm{Fc} 2$, dan Fc3 yang diperoleh diuji alkaloid dengan penyemprotan menggunakan pereaksi Dragendorf. Hasil penyemprotan dengan pereaksi Dragendorf diperoleh hasil bahwa noda Fc2 menunjukkan hasil positif terhadap alkaloid ditandai dengan timbulnya bercak coklat kemerahan pada spot yang terbentuk. Terhadap Fc2 (hijau kebiruan) kemudian dilakukan uji kemurnian 
dengan KLT menggunakan berbagai macam eluen yang ditunjukkan pada Tabel 3.

Tabel 3: Uji kemurnian isolat Fc2 dengan berbgai eluen

\begin{tabular}{cccc}
\hline No & Eluen & $\begin{array}{c}\text { Jumlah } \\
\text { Noda }\end{array}$ & $\mathrm{Rf}$ \\
\hline 1 & Aseton & 1 noda & 0,83 \\
2 & Diklorometana & 1 noda & 0,45 \\
3 & n-butanol & 1 noda & 0,90 \\
4 & Metanol & 1 noda & 0,64 \\
5 & Kloroform & 1 noda & 0,91 \\
6 & Kloroform : n-heksana & 1 noda & 0,22 \\
\hline
\end{tabular}

Dari hasil uji kemurnian pada isolat Fc2 menunjukkan bahwa isolat telah murni yang ditunjukkan dengan menghasilkan noda tunggal yang berwarna hijau kebiruan. Filtrat kemudian diuapkan untuk menghilangkan pelarut yang terkandung di dalamnya sehingga dihasilkan padatan alkaloid berwarna kuning kemerahan. Terhadap padatan alkaloid tersebut kemudian diidentifikasi menggunakan Spektrofotometer UV-Vis, FTIR, dan LC-MS.

\section{Analisis Isolat}

Isolat alkaloid Fc2 yang didapatkan, dianalisis menggunakan Spektrofotometer UV-Vis, dari spektrum yang diperoleh diketahui bahwa isolat tersebut mempunyai panjang gelombang maksimum ( $\lambda$ max) pada $338 \mathrm{~nm}$. Spektrum UV-Vis isolat alkaloid disajikan pada Gambar 4 .

Hasil analisis menggunakan Spektrofotometer UVVis diperkuat dengan penenlitian dari $[6,7]$ yang memperoleh panjang gelombang maksimal pada piperin adalah pada $343 \mathrm{~nm}$ menggunakan pelarut metanol.

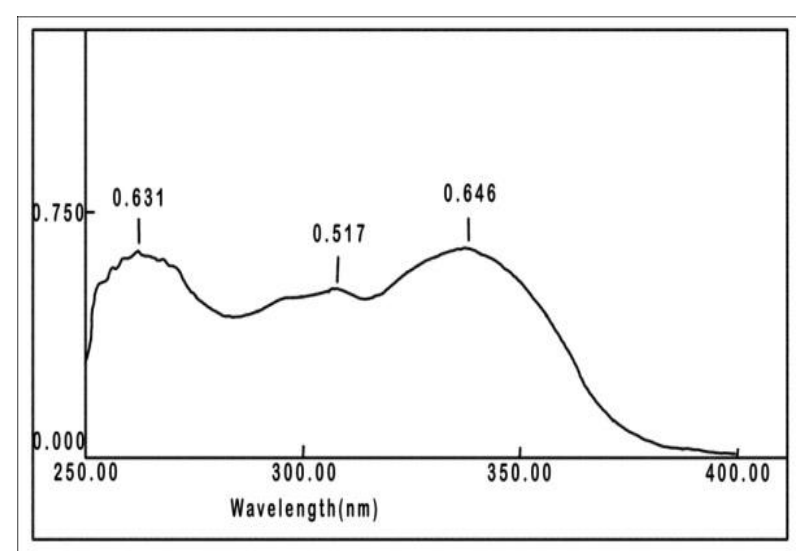

Gambar 4. Spektrum UV-Vis isolat alkaloid

Untuk mengetahui keberadaan gugus fungsi yang terdapat pada isolat alkaloid selanjutnya dilakukan analisis dengan FTIR. Hasil spektrogram dari FTIR dapat dilihat pada Gambar 5.
「

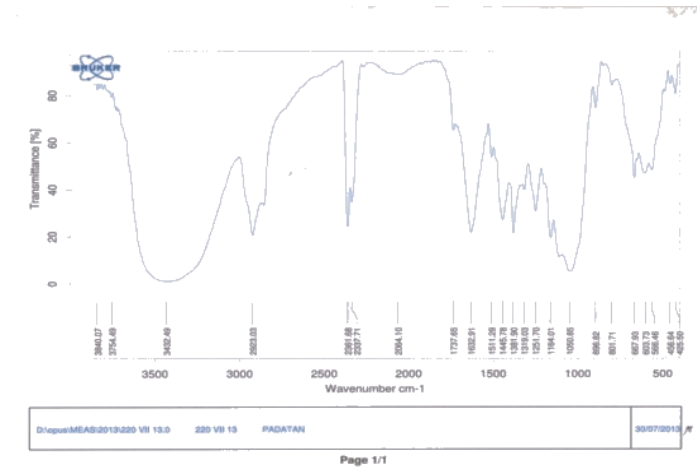

Gambar 5. Spektrogram FTIR isolat alkaloid

Berdasarkan hasil analisis dengan Spektrofotometer UV-Vis dan FTIR, isolat murni merupakan senyawa alkaloid yang mengandung gugus $\mathrm{C}-\mathrm{N}$ pada bilangan gelombang $2361,68 \mathrm{~cm}^{-1}$ dan 2337,71 $\mathrm{cm}^{-1}, \mathrm{C}=\mathrm{O}$ amida pada bilangan gelombang $1632,91 \mathrm{~cm}^{-1}$, $\mathrm{C}=\mathrm{C}$ aromatik pada bilangan gelombang $1511,29 \mathrm{~cm}^{-1}, \mathrm{C}-$ $\mathrm{O}$ eter pada bilangan gelombang $1050,85 \mathrm{~cm}^{-1}$, dan $\mathrm{C}-\mathrm{H}$ alifatik pada bilangan gelombang $2923,03 \mathrm{~cm}^{-1}$ dan $2812,34 \mathrm{~cm}^{-1}$.

Isolat alkaloid kemudian dianalisis dengan Liquid Cromatography-Mass Spectroscopy (LC-MS) untuk mengetahui berat molekul. Kromatogram isolat alkaloid ditampilkan pada Gambar 6.

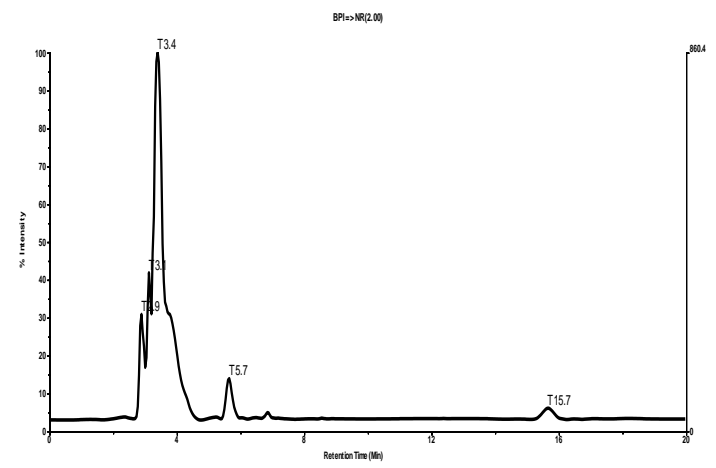

Gambar 6. Kromatogram LC isolat alkaloid

Hasil analisis menggunakan LC menunjukkan bahwa isolat tersebut belum murni yang ditunjukkan munculnya 5 puncak. Berikut spektrogram isolat alkaloid dari puncak yang tertinggi pada waktu retensi 3,4 menit yang ditampilkan pada Gambar 7 .

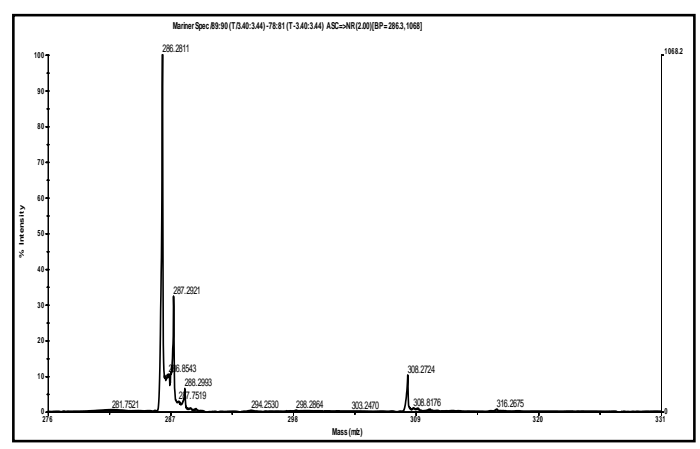

Gambar 7. Spektrogram MS isolat alkaloid 
Hasil spektrogram MS dari puncak 3 menunjukkan waktu retensi pada 3,4 menit dan harga berat molekul senyawa alkaloid $[\mathrm{M}+\mathrm{H}]^{+}$sebesar $286,2811 \mathrm{~g} / \mathrm{mol}$. Berat molekul yang diperoleh diduga merupakan senyawa piperin, hal ini diperkuat berdasarkan penelitian [8] menggunakan metode LC-MS yang memperoleh berat molekul dari piperin adalah sebesar 286,3 g/mol.

Berdasarkan data-data yang diperoleh dari hasil analisis dan sesuai dengan penelitian [6-8], diduga isolat alkaloid yang telah diisolasi dari rimpang lengkuas merah mengandung senyawa piperin $\left(\mathrm{C}_{17} \mathrm{H}_{19} \mathrm{NO}_{3}\right)$. Struktur molekul dari piperin ditunjukkan pada Gambar 8.<smiles>O=C(/C=C/C=C/c1ccc2c(c1)OCO2)N1CCCCC1</smiles>

Gambar 8. Struktur alkaloid piperin [9]

\section{Kesimpulan}

Senyawa yang telah diisolasi dari rimpang lengkuas merah (Alpinia purpurata) merupakan golongan alkaloid. Hasil analisis menggunakan spektrofotometer UV-Vis, FTIR dan LC-MS menunjukkan bahwa isolat alkaloid diduga mengandung senyawa piperin $\left(\mathrm{C}_{17} \mathrm{H}_{19} \mathrm{NO}_{3}\right)$.

\section{Daftar Pustaka}

[1] Fajar Budi Laksono, Enny Fachriyah, Dewi Kusrini, Isolasi dan Uji Antibakteri Senyawa Terpenoid Ekstrak N-Heksana Rimpang Lengkuas Merah (Alpinia purpurata), Jurnal Kimia Sains dan Aplikasi, 17, 2, (2014) 37-42

[2] Fauziah Muhlisah, Temu-temuan dan Emponempon Budidaya dan Manfaatnya, Kanisius, Yogyakarta, (1999) 51-52

[3] Ratna Susilaningsih, Isolasi, Identifikasi dan Uji Toksisitas Senyawa Alkaloid Fraksi Etil Asetat Rimpang Lengkuas Merah (Alpinia galanga), Kimia, Universitas Diponegoro, Semarang

[4] Hasnah Mohd Sirat, Md Liamen, Chemical constituents of Alpinia purpurata, Pertanika Journal of Science \& Technology, 3, 1, (1995) 67-71

[5] D Manohara, K Mulya, A Purwantara, D Wahyuno, 6.4 Phytophthora capsici on Black Pepper in Indonesia, Diversity and management of Phytophthora in Southeast Asia, (2004) 132

[6] V Junise, P Shibin, S Senthila, RS Rajesh, Isolation, identification and antimycobacterial evaluation of piperine from Piper longum, Der Pharmacia Lettre, 4, 3, (2012) 863-868

[7] Reimmel Kwame Adosraku, James Oppong Kyekyeku, Isaac Yaw Attah, Characterization and HPLC quantification of piperine isolated from Piper guineense (fam. Piperaceae), International Journal of Pharmacy and Pharmaceutical Sciences, 5, Issue 1, (2013)

[8] Xiu-Mei Wang, Qi-Zhi Zhang, Jian Yang, R_H Zhu, Jun Zhang, Li-Jing Cai, Wen-Xing Peng, Validated
HPLC-MS/MS method for simultaneous determination of curcumin and piperine in human plasma, Tropical Journal of Pharmaceutical Research, 11, 4, (2012) 621-629 http://dx.doi.org/10.4314/tjpr.v11i4.13

[9] Narendra Kumar Singh, Pramod Kumar, Devendra Kumar Gupta, Satyendra Singh, Varun Kumar Singh, UV-spectrophotometric method development for estimation of piperine in Chitrakadi Vati, Der Pharmacia Lettre, 3, 3, (2011) 178-182 